\title{
Clenbuterol toxicity: a NSW Poisons Information Centre experience
}

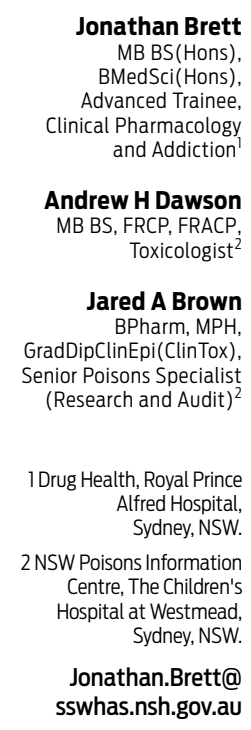

MJA 2014; 200: 219-221 doi: 10.5694/mjal3.10982 lenbuterol is a $\beta 2$-adrenergic agonist with a long half-life of around 25-40 hours and high bioavailability, ${ }^{1}$ currently registered in Australia as a Schedule 4 medicine for veterinary use. ${ }^{2}$ It is marketed in tablet, gel and injectable forms as an equine bronchodilator and a bovine tocolytic agent. Its anabolic properties have seen it used in food-producing animals to increase lean meat yield. ${ }^{3}$ However, concerns about toxicity to humans from contaminated meat led to its use for this purpose being banned in the United States in 1991 and the European Union in 1996. Since then, there have been outbreaks of clenbuterol toxicity from contaminated meat across Europe and China, ${ }^{4-6}$ and outbreaks of clenbuterol contamination of heroin. ${ }^{7}$

The spectrum of toxicity in humans includes sympathomimetic effects such as restlessness, tachycardia and tachyarrhythmias, ${ }^{8}$ gastrointestinal disturbances and rhabdomyolysis, and metabolic disturbances such as hyperglycaemia and hypokalaemia. There have also been case reports of myocardial ischaemia in otherwise healthy people, ${ }^{9,10}$ and of respiratory distress in adults after nasal insufflation. ${ }^{11}$

In the past 10 years, a number of elite athletes have used clenbuterol as a performance-enhancing drug, leading to its ban by the International Olympic Committee and World AntiDoping Agency. ${ }^{12,13}$

In humans, clenbuterol has been used in tablet form as a bronchodilator at doses of $20-40 \mu \mathrm{g}$ daily, ${ }^{14}$ but it is not registered with the Australian Therapeutic Goods Administration. More recently, the use of clenbuterol as a slimming and anabolic agent has been publicised in the media in stories of use by celebrities. ${ }^{15}$ There is concern about the increasing unprescribed use of clenbuterol by the general public and the ease of online purchase of this drug. Although poisons centres in the US and France have published observational reports on the level of use and spectrum of toxicity of clenbuterol, ${ }^{14,16}$ the situation in Australia remains unknown.

\section{Abstract}

Objective: To describe the epidemiology and toxicity of clenbuterol in exposures reported to the NSW Poisons Information Centre (NSWPIC).

Design and setting: Retrospective observational study analysing data from all calls about clenbuterol exposure recorded in the NSWPIC database from 1 January 2004 to 31 December 2012. The NSWPIC coversthe Australian jurisdictions New South Wales, Tasmania and the Australian Capital Territory 24 hours a day and provides after-hours cover for the rest of Australia for 7 nights each fortnight.

Main outcome measures: Total number of exposures, source of call (hospital, health care worker, member of the public), time from exposure to call, reasons for drug use, clinical features and advice given.

Results: Callers reported 63 exposures to clenbuterol, with a dramatic increase from three in 2008 to 27 in 2012 . Of the 63 calls, 35 were from hospital, two from paramedics, one from general practice and 21 direct from the public. At least 53 patients ( $84 \%$ ) required hospitalisation. The commonest reasons for use were bodybuilding and slimming. The most common features were tachycardia (24 patients), gastrointestinal disturbance (16) and tremor (11). Exposure was also associated with cardiotoxicity including one cardiac arrest in a 21-year-old man.

Conclusion: Although a well recognised doping issue among elite athletes, clenbuterol use has spread out into the general public, especially during 2012, and should be considered in patients using bodybuilding or slimming products who present with protracted sympathomimetic features. The potential for misuse of this substance requires reconsideration of its current poison schedule registration and its availability.

Here, we describe NSW Poisons Information Centre (NSWPIC) reports of clenbuterol exposures.

\section{Methods}

The NSWPIC receives around 110000 calls annually $-50 \%$ of all poisoning-related calls in Australia. The NSWPIC handles calls from New South Wales, Tasmania and the Australian Capital Territory from 6 am to midnight, and provides overnight cover for the whole nation for 7 of 14 days per fortnight.

We retrospectively reviewed the NSWPIC database and the database of the NSWPIC toxicologist for the 9 years from 1 January 2004 to 31 December 2012 using the search terms "clenbuterol", "ventipulmin", "oralject", "planipart", "broncopulmin" and "claire".

We manually reviewed all cases from this search for inclusion; those included were categorised by reported source of call, formulation type, reason for use and clinical features. Other variables we examined were age, sex, hospitalisation status and geographical location. Exposure was categorised as unique episodes rather than calls received. Calls referred to toxicologists are also recorded in a separate database and include more clinical details; we present significant toxicities recorded in this database.

We used the median and range to describe data and performed statistical analyses with Microsoft Excel (Microsoft Corporation).

Ethics approval for this study was granted by the human research ethics committee of the Sydney Children's Hospitals Network.

\section{Results}

\section{NSWPIC database}

There were 63 unique episodes related to clenbuterol exposure over the 9-year study period, with a worrying increase from three episodes in 2004 to 27 episodes in 2012 and a particularly notable increase in the last year (Box 1). Most of the calls (46) were from NSW, but 17 were from interstate. 
1 Calls to the NSW Poisons Information Centre about 63 unique episodes of clenbuterol exposure from 1 January 2004 to 31 December 2012

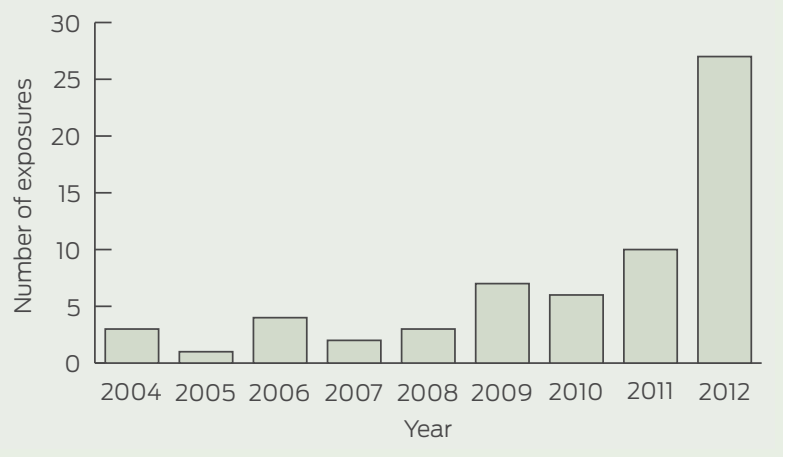

2 Clinical features relating to 63 unique episodes of clenbuterol exposure reported by callers to the NSW Poisons Information Centre from 1 January 2004 to 31 December 2012

Clinical features

Number

$\begin{array}{ll}\text { No symptoms } & 5 \\ \text { Tachycardia and/or palpitations } & 24 \\ \text { Gastrointestinal disturbances } & 16 \\ \text { (nausea, vomiting, diarrhoea) } & 11 \\ \text { Tremor } & 10 \\ \text { Anxiety and/or agitation } & 7 \\ \text { Diaphoresis } & 5 \\ \text { Headaches } & 4 \\ \text { Hypertension } & 4 \\ \text { Hypokalaemia } & 3 \\ \text { Abdominal pain } & 3 \\ \text { Chest pain } & 3 \\ \text { ST-segment changes on electrocardiogram } & 3 \\ \text { Hypotension } & 2 \\ \text { Hyperglycaemia } & 2 \\ \text { Elevated troponin level } & 2 \\ \text { Cardiac arrest } & 1\end{array}$

Twenty-five patients were female, 33 were male and sex was not recorded in five exposures. Sixty calls about exposures were for adults and three for children (up to 16 years). Exposures among children comprised an intentional ingestion by a 16 -yearold and unintentional ingestions by a 1-year-old and a 2-year-old. The median age for all patients with clenbuterol exposure was 21 years (range, 1-83 years). Calls were taken from both metropolitan and regional areas and the numbers of calls appeared to be proportional to population size in those areas.

Clenbuterol was mostly taken in the veterinary liquid or gel form (24 exposures) at a median of $2 \mathrm{~mL}$ (range, $0.5-20 \mathrm{~mL}$ ) or two "scoops" (range, 1-2 scoops). The actual dose is highly variable between liquid formu- lations. Two people took tablets (one and three tablets, respectively) and of the eight episodes in which the dose was known, the median dose was $0.8 \mathrm{mg}$ (range, 0.08-5000 mg).

Thirty-six calls were from hospitals, two from paramedics, one from a general practice and 21 directly from the public. Caller background was not recorded on four occasions. Of the calls from the public, 14 patients were referred to hospital, three were referred to a general practitioner and four were advised to stay at home.

When recorded, the reasons for use included slimming (12 exposures) and bodybuilding (four), but also selfharm (two). There were three unintentional exposures.

At least 53 patients (84\%) required hospitalisation. In only five calls about exposures were patients asymptomatic. The commonest clinical features in those with symptoms were tachycardia (24 patients), gastrointestinal disturbances including nausea, vomiting and diarrhoea (16), and tremor (11). There were a range of other features (Box 2), most notably hypokalaemia (four patients), chest pain (three), ST-segment changes on electrocardiogram (ECG; three), an increase in troponin level (two) and cardiac arrest (one). In the 14 exposures for which the time of ingestion was recorded, most calls were made after exposure in the preceding 6-24 hours. Eight people were recorded as taking clenbuterol over a period of weeks to months.

\section{Case reports}

Analysis of NSWPIC toxicologist records revealed three noteworthy cases. The first was an elderly man who drank an unknown amount of clenbuterol from an unlabelled bottle, thinking it was water. He had a history of ischaemic heart disease and diabetes, and presented to the emergency department soon after the ingestion with hypotension (blood pressure, 90/70 $\mathrm{mmHg}$ ) and sinus tachycardia on ECG (heart rate, 140 beats/min). His hypotension resolved with fluid resuscitation. An esmolol infusion was started, but 8 hours later the hospital supply of esmolol ran out. Given that his heart rate was still high (128 beats/min), he was given metoprolol, orally, with good effect. His troponin level (high sensitivity) at 12 hours had risen to $403 \mathrm{ng} / \mathrm{L}$ (reference interval [RI], <14 ng/L).

The second case was that of a dosing error by a young bodybuilder who took $7 \mathrm{~mL}$ instead of seven drops of clenbuterol solution. His heart rate at presentation was 235 beats/min and, after an ECG, he was thought to have a supraventricular tachycardia, although his blood pressure was 133/ $82 \mathrm{mmHg}$. His potassium level was $2.2 \mathrm{mmol} / \mathrm{L}$ (RI, 3.5-5 mmol/L) and he was agitated, so was given diazepam. An esmolol infusion was started, but after 12 hours the hospital supplies had again run out, so his therapy was changed to metoprolol with good effect.

The third case was that of a young man who had been using clenbuterol for the preceding 8 weeks for bodybuilding, and may have increased his dose in the few days before the call to the NSWPIC. He had a cardiac arrest while playing sport and was immediately treated with cardiopulmonary resuscitation by a bystander, with return of spontaneous circulation 9 minutes later. He subsequently made a good recovery.

\section{Discussion}

The number of calls to the NSWPIC about clenbuterol toxicity is increasing. Calls indicate that clenbuterol is predominantly being used for slimming and bodybuilding, and that it is the veterinary product that is being used. However, it was not possible to determine where this product was being sourced.

The misuse of this drug poses the secondary risk of accidental poisoning of children. It is often taken in doses far exceeding the safe therapeutic doses in humans, and order-of-magnitude dosing errors occur. Exposure calls did not show clustering in urban or rural areas.

Clenbuterol use produced a range of sympathomimetic toxicities, which were often prolonged (as calls were most often made 6 to 24 hours after exposure) and occasionally associated with cardiac damage. The case of cardiac arrest is particularly alarming, although we do not know whether this individual had any underlying 
undiagnosed structural heart disease or cardiac channelopathy.

Although we did not record concomitant medication use in our study, a descriptive US study found that clenbuterol is often taken with thyroxine, anabolic steroids and products containing caffeine and stimulants, which appears to exacerbate toxicity. ${ }^{14}$

Limitations of our descriptive study include non-standardised methods of telephone enquiry and coding which is likely to have led to underrecording of clenbuterol exposures. Our study presents exposures reported to the NSWPIC, and so is likely to significantly underestimate total clenbuterol exposures. There was also a lack of outcome data from hospital admissions due to the limited information provided by phone, and follow-up not being routinely performed by Australian poisons information centres. This is predominantly a NSW experience with limited data from the rest of the country (resulting from the on-call structure) and so our findings are not generalisable to the whole country.

Clenbuterol exposure should be considered in patients presenting with prolonged sympathomimetic effects after taking bodybuilding or slimming products. Treatments described in other studies include charcoal, benzodiazepines, electrolyte replacement and intravenous fluids. $\beta$-Blockers are often used, but as our case descriptions illustrate, hospital supplies of esmolol are often exhausted and treatment with metoprolol appears to be sufficient. However, if $\beta$-blocker therapy is being considered, care should be taken to differentiate clenbuterol toxicity from other sympathomimetic overdoses with unknown ingestants because there is a theoretical risk of hypertensive crisis with unopposed $\alpha$-adrenergic agonism.

Given the increasing use of nonprescribed clenbuterol and the associated toxicity, it has been argued that sales and use should be restricted by attaching an appendix D or B to the Schedule 4 registration of this agent, thus putting it into the same category as benzodiazepines and anabolic steroids. Diversion of veterinary products for misuse in humans is a longstanding issue $\mathrm{e}^{17}$ that also should be tackled.

Competing interests: No relevant disclosures.

Received 30 Jul 2013, accepted 1 Oct 2013.

1 Couet W, Girault J, Reigner BG, et al. Steady-state bioavailability and pharmacokinetics of ambroxol and clenbuterol administered alone and combined in a new oral formulation. Int J Clin Pharmacol Ther Toxicol 1989; 27: 467-472.

2 ComLaw. Poisons Standard 2012 F2012L01200. Schedule 1 - Standard for the Uniform Scheduling of Medicines and Poisons No. 3. Commonwealth of Australia, 2012. http:// www.comlaw.gov.au/Details/F2012L01200 (accessed Aug 2013).

3 Mitchell GA, Dunnavan G. Illegal use of betaadrenergic agonists in the United States. J Anim Sci 1998; 76: 208-211.

4 Barbosa J, Cruz C, Martins J, et al. Food poisoning by clenbuterol in Portugal. Food Addit Contam 2005; 22: 563-566.

5 Salleras L, Dominguez A, Mata E, et al. Epidemiologic study of an outbreak of clenbuterol poisoning in Catalonia, Spain. Public Health Rep 1995; 110: 338-342.
6 Kuiper HA, Noordam MY, van Dooren-Flipsen MM et al. Illegal use of beta-adrenergic agonists: European Community. J Anim Sci 1998; 76: 195-207.

7 Hoffman RS, Kirrane BM, Marcus SM; Clembuterol Study Investigators. A descriptive study of an outbreak of clenbuterol-containing heroin. Ann Emerg Med 2008; 52: 548-553.

8 Daubert GP, Mabasa VH, Leung VW, Aaron C. Acute clenbuterol overdose resulting in supraventricular tachycardia and atrial fibrillation. J Med Toxicol 2007; 3: 56-60.

9 Kierzkowska B, Stańczyk J, Kasprzak JD. Myocardial infarction in a 17-year-old body builder using clenbuterol. Circ J 2005; 69: 1144-1146.

10 Goldstein DR, Dobbs T, Krull B, Plumb VJ. Clenbuterol and anabolic steroids: a previously unreported cause of myocardial infarction with normal coronary arteriograms. South Med J 1998 91: 780-784.

11 Schechter E, Hoffman RS, Stajic M, et al. Pulmonary edema and respiratory failure associated with clenbuterol exposure. Am J Emerg Med 2007; 25: 735.el-e3.

12 Chan TY. Health hazards due to clenbuterol residues in food. J Toxicol Clin Toxicol 1999; 37: 517-519.

13 World Anti-Doping Agency. WADA statement on clenbuterol 2011. http://www.wada-ama.org/en/ media-center/archives/articles/wadastatement-on-clenbuterol (accessed Jun 2013).

14 Spiller HA, James KJ, Scholzen S, Borys DJ. A descriptive study of adverse events from clenbuterol misuse and abuse for weight loss and bodybuilding. Subst Abus 2013; 34: 306-312.

15 Guest K. Clenbuterol: the new weight loss wonder drug gripping planet zero. The Independent 2014; 4 Feb. http://www.independent.co.uk/life-style/ health-and-families/health-news/clenbuterolthe-new-weightloss-wonder-drug-grippingplanet-zero-441059.html (accessed Feb 2014).

16 Pulce C, Saviuc P, Pineau X, et al. Clenbuterol: retrospective study of cases from the French poison and toxicovigilance centres between 2000 and 2008 [abstract]. Clin Toxicol 2011; 49: 215.

17 Lust EB, Barthold C, Wichman TO, et al. Human health hazards of veterinary medications: information for emergency departments. J Emerg Med 2011; 40: 198-207. 